\title{
Removal of nitrate using modified pumice as adsorbent for reducing groundwater pollution
}

\author{
Shinta Indah $^{1 *}$, Denny Helard ${ }^{2}$, Gusti Lusiani $^{1}$, and Diana Hapsari ${ }^{2}$ \\ ${ }^{1}$ Department of Environmental Engineering, Faculty of Engineering, Andalas University, Padang 25163 \\ ${ }^{2}$ Departemen of Applied Life Science, Faculty of Applied Biological Science, Gifu University
}

\begin{abstract}
Nitrate adsorption onto the physically and chemically modified pumice was investigated as an effort for reducing groundwater pollution. The treatments were heating at temperatures of $300^{\circ} \mathrm{C}, 450^{\circ} \mathrm{C}$, and $600^{\circ} \mathrm{C}$ for physical and soaking in acid solutions $\left(\mathrm{HCl}, \mathrm{H}_{2} \mathrm{SO}_{4}\right.$, and $\left.\mathrm{HNO}_{3}\right)$ for chemical treatments. The adsorption was performed in a batch system at room temperature $\left(25 \pm 1^{\circ} \mathrm{C}\right)$ with the optimum condition $(\mathrm{pH}$ $4 ; 0.3 \mathrm{~g} / \mathrm{L}$ of adsorbent dose; $<63 \mu \mathrm{m}$ of adsorbent diameters and 30 minutes of contact time). The results indicated that the physically and chemically modified pumice resulted in increasing removal efficiency and nitrate uptake compared to the natural pumice. The highest removal efficiency and nitrate uptake were achieved from $300^{\circ} \mathrm{C}$ of heating temperatures $(62.04 \%$ and $155.09 \mathrm{mg} / \mathrm{g})$ and $\mathrm{H}_{2} \mathrm{SO}_{4}$ for the acid solution $(83.30 \%$ and $208.25 \mathrm{mg} / \mathrm{g})$, while by using the natural pumice only reached $57.02 \%$ and $142.55 \mathrm{mg} / \mathrm{g}$. The SEM images of the modified pumice confirmed the change in the surface morphology of pumice including the pore structure and surface area which can be proper sites for adsorption of pollutants. This study demonstrated that physical and chemical modification could be the potential treatment to increase the removal efficiency and nitrate uptake of the natural pumice, thus can solve the problem of groundwater pollution.
\end{abstract}

\section{Introduction}

Due to its harmful effect, contamination of nitrate in groundwater has become a serious environmental problem. In water resources, the most common sources of nitrate are the discharge of raw wastewater, biodegradation of nitro-organic compounds, septic tank effluents, fertilizers, and pharmaceuticals. In groundwater, nitrate is possibly the most widespread contaminant, causing a serious threat to drinking water supplies due to its high water solubility [1-3]. High nitrate concentrations in drinking water cause health problems, such as cancer due to the formation of nitrosamine and cyanosis among children. Therefore, the US Environmental Protection Agency (EPA) and World Health Organization (WHO) set the maximum acceptable contaminant level of nitrate for drinking water to be 45 $\mathrm{mg} / \mathrm{L}$ and $50 \mathrm{mg} / \mathrm{L}$ of nitrate, respectively [4].

Adsorption is an effective technique for nitrate removal, as it is an effective alternative for removing ions from water, economical, easy design, and operation as well as low costs [5-7]. For nitrate removal, different adsorbents have been studied [8] such as geomaterials like kaolinite [9], and pumice [10,11]. Since in several cases the geomaterials have lower adsorption capacity, various methods have been proposed for the modification of geomaterials to improve their adsorption capacity. Physical treatment by heating process and chemical treatment by using chemicals including acids, bases, minerals, and the oxidizing agent has been evaluated for adsorbent modification. Those treatments proved could improve the adsorption capacities of the adsorbent due to the changes in the pore structure, surface chemical functional groups, and specific surface area of the adsorbent. [12].

Pumice is one of natural pozzolan which has low weight, porous structure, and a large surface area. In addition to its applications in the construction industry, researchers in the field of water and wastewater treatments have been studied a possible extension of the pumice to become an adsorbent [5, 13-15]. The objective of the present study is to evaluate the adsorption capacity of physically and chemically modified pumice on nitrate removal. This is one of the efforts for reducing or solving the groundwater pollution caused by nitrate.

\section{Material and Methods}

\subsection{Reagent}

Nitrate stock solution was provided by dissolving potassium nitrate $\left(\mathrm{KNO}_{3}\right)$ in distilled water. The acid solutions i.e. $\mathrm{HCl}, \mathrm{H}_{2} \mathrm{SO}_{4}$, and $\mathrm{HNO}_{3}$ were used for chemical modification of the pumice

\footnotetext{
* Corresponding author: shintaindah@eng.unand.ac.id
} 


\subsection{Modification of Pumice}

The pumice was collected from the riverside of Sungai Pasak, West Sumatera, Indonesia. To remove any impurities, pumice was washed with distilled water and dried at room temperature $\left(25 \pm 10^{\circ} \mathrm{C}\right)$. The pumice was ground and sieved to obtain particle size fractions of $<63$ $\mu \mathrm{m}$ before modification. A physical modification was conducted by heating at a temperature of $300^{\circ} \mathrm{C}, 450^{\circ} \mathrm{C}$, and $600^{\circ} \mathrm{C}$ for $3 \mathrm{~h}$. Chemical modification was carried out by soaking and stirring the pumice $\mathrm{HCl} 1 \mathrm{M}, \mathrm{H}_{2} \mathrm{SO}_{4} 1 \mathrm{M}$, and $\mathrm{HNO}_{3} 1 \mathrm{M}$ for $4 \mathrm{~h}$ and then washing by distilled water and drying at $130^{\circ} \mathrm{C}$ for $3 \mathrm{~h}$.

\subsection{Batch adsorption experiment}

Batch adsorption experiment was conducted at room temperature $\left(25 \pm 1^{\circ} \mathrm{C}\right)$ with the optimum condition: $\mathrm{pH} 4$; $<63 \mu \mathrm{m}$ of adsorbent diameters; $0.3 \mathrm{~g} / \mathrm{L}$ of adsorbent dose and 30 minutes of contact time. These conditions were obtained from the previous research. In each experiment, $100 \mathrm{~mL}$ of nitrate solutions with $75 \mathrm{mg} / \mathrm{L}$ of initial concentration were treated with seven kinds of adsorbents in a set of Erlenmeyer flasks. A shaker machine was used to shake them at a speed of $100 \mathrm{rpm}$ for 30 minutes of contact time. Then, the mixture was filtered through a $0.45 \mu \mathrm{m}$ membrane filter to separate the adsorbents and supernatant. The concentration of nitrate in the supernatants was measured using spectrophotometer UVVis (Shimadzu, UV-2600). The difference between the initial and final nitrate concentrations of the solutions was calculated as the number of nitrate ions adsorbed by the pumice. All experiments were conducted in triplicate and the averaged values of replicate tests were presented as the results.

The following mass-balance equations were used to calculate the removal efficiency and the nitrate uptake $\left(\mathrm{q}_{\mathrm{e}}\right.$, $\mathrm{mg} / \mathrm{g}$ ) on natural and modified pumice:

$$
\begin{aligned}
\operatorname{Removal}(\%) & =\frac{c_{0}-C_{e}}{C_{0}} \times \mathbf{1 0 0} \% \\
\boldsymbol{q}_{e} & =\frac{c_{0}-C_{e}}{m} \times \mathrm{V} \ldots
\end{aligned}
$$

where $C_{0}$ is the nitrate's initial concentration $(\mathrm{mg} / \mathrm{L}), C_{\mathrm{e}}$ is the nitrate's equilibrium concentration $(\mathrm{mg} / \mathrm{L}), V$ is the volume of the solution (L), and $m$ is the mass of the pumice (g).

\subsection{Analysis of surface morphology of pumice}

a scanning electron microscopy (SEM, model S-3400N, Hitachi, Japan) was employed to observe the surface morphology of pumice.

\section{Results dan discussion}

\subsection{Physically modified pumice}

The removal of efficiencies and nitrate uptakes of natural and physically modified pumice are shown in Fig. 1.
Physical modification of pumice was carried out by heat treatment at a temperature of $300^{\circ} \mathrm{C}, 450^{\circ} \mathrm{C}$, and $600^{\circ} \mathrm{C}$. The nitrate removal efficiency by using the natural pumice was $57.02 \%$, while by the modified heating pumice, the removal efficiency reached $62.04 \%, 57.24 \%$, and $29.86 \%$, respectively at $300^{\circ} \mathrm{C}, 450^{\circ} \mathrm{C}$, and $600^{\circ} \mathrm{C}$. The nitrate uptake obtained by using the natural pumice was $142.55 \mathrm{mg} / \mathrm{g}$, whereas by modified heating pumice at $300^{\circ} \mathrm{C}, 450^{\circ} \mathrm{C}$, and $600^{\circ} \mathrm{C}$ were $155.09 \mathrm{mg} / \mathrm{g}, 143.11$ $\mathrm{mg} / \mathrm{g}$, and $74.64 \mathrm{mg} / \mathrm{g}$, respectively. It was observed that the removal efficiency and nitrate uptake increased in using modified pumice by heating at $300^{\circ} \mathrm{C}$ and $450^{\circ} \mathrm{C}$. However, the lowest removal efficiency and nitrate uptake were found at the modified heating pumice at $600^{\circ} \mathrm{C}$.

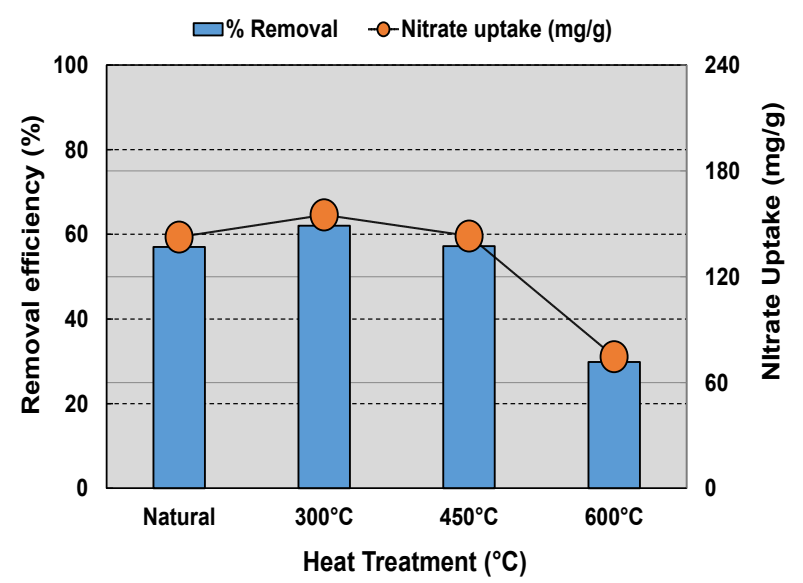

Fig 1. Removal efficiencies and nitrate uptakes of natural and physically modified pumice.
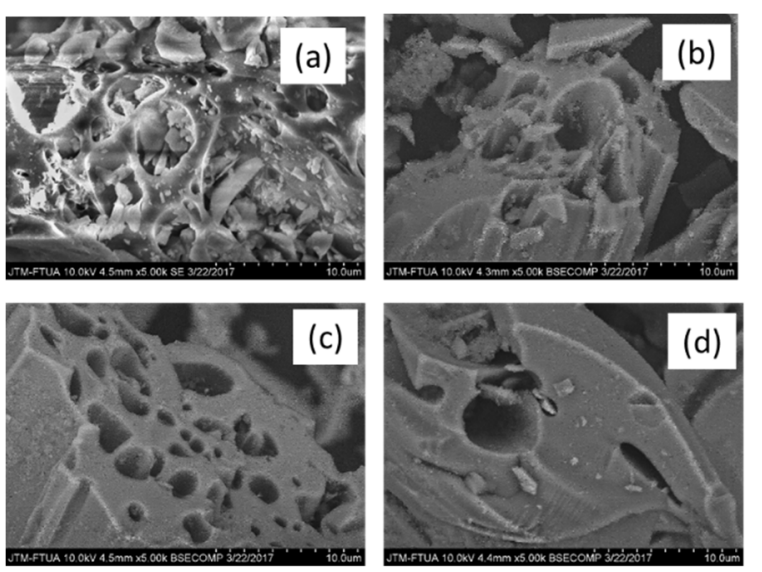

Fig 2. The SEM images (5000x) of natural pumice (a) and physically modified pumice by heat treatment at $300^{\circ} \mathrm{C}(\mathrm{b})$, $450^{\circ} \mathrm{C}(\mathrm{c})$, and $600^{\circ} \mathrm{C}(\mathrm{d})$.

Generally, physical modification results in the enhancement of physical characteristics (total pore volume and BET area) of the adsorbent. The calcining process or heat treatment causes a change in the porosity and the chemical composition of the adsorbent surface. The heat treatment also revealed a significant increase in pore volume and specific surface area of the adsorbent and may increase its adsorption ability [16]. Nevertheless, the higher temperature leads to damage in the adsorbent 
structure and affects the adsorption process, as observed from the experiment with $600^{\circ} \mathrm{C}$ of heating temperature.

Fig 2 presents the SEM images of the natural and physically modified pumice. A relatively large number of pores is shown in the natural pumice with some of the pores are covered by other compounds (Fig 2a). The physically modified pumice heated at $300^{\circ} \mathrm{C}$ and $450^{\circ} \mathrm{C}$ showed a greater number of open pores (Fig $2 \mathrm{~b}$ and $2 \mathrm{c}$ ). It demonstrates that heat treatment increased the pore volume and surface area of the pumice, which also increased its adsorption capacity. Yet, the modified heating pumice at $600^{\circ} \mathrm{C}$ has fewer pores, as shown in Fig $2 \mathrm{~d}$, due to damage in the structure of the pumice pores caused by overheating temperatures

\subsection{Chemically modified pumice}

Chemical modification of pumice was performed by acid immersion of pumice. An increase in removal efficiency was observed by using the chemically modified pumice than the natural pumice, as shown in Fig 3. Using the natural pumice, $57.02 \%$ of nitrate removal efficiency was obtained while by modified pumice soaked in $\mathrm{HCl}, \mathrm{H}_{2} \mathrm{SO}_{4}$ and $\mathrm{HNO}_{3}$ removal efficiencies increased to $72.15 \%$, $83.30 \%$, and $57.87 \%$, respectively. The increase in removal efficiency was followed by an increase in nitrate uptake. The nitrate uptake observed by using the natural pumice was $142.55 \mathrm{mg} / \mathrm{g}$ while using modified pumice soaked in $\mathrm{HCl}, \mathrm{H}_{2} \mathrm{SO}_{4}$ and $\mathrm{HNO}_{3}$ reached $180.37 \mathrm{mg} / \mathrm{g}$, $208.25 \mathrm{mg} / \mathrm{g}$, and $144.67 \mathrm{mg} / \mathrm{g}$, respectively.

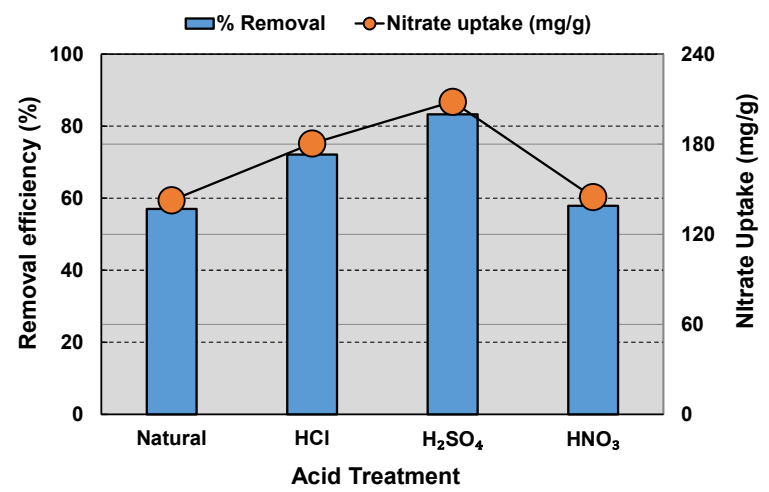

Fig 3. Removal efficiencies and nitrate uptakes of natural and chemically modified pumice

Acid treatment of adsorbent is applied to oxidize the porous surface of the adsorbent. It caused increases in the acidic property and also removes the mineral elements, as well as improved the hydrophilic nature of the surface [17]. Sulfuric and nitric acid is the most widely studied ones besides some other acids used for the purpose. The purpose of the acidic treatment of pumice was to improve the positive surface charge of the adsorbent and improve its sorption capacity [18]. Besides, soaking the adsorbent in acid solution may dissolve the impurities on the surface of the pores of the adsorbent, increasing the pore volume, surface area, and adsorption capability of the adsorbent [19].

The results obtained that the highest removal efficiency and nitrate uptake were found using modified pumice by soaking in $\mathrm{H}_{2} \mathrm{SO}_{4} 1 \mathrm{M}$, followed by $\mathrm{HCl}$ and $\mathrm{HNO}_{3}$. It indicated the different interactions between the acid solution and the pumice. This finding is supported by the result obtained by Soleimani et al (2019) in investigating the efficacy of acid-modified pumice for the removal of humic acid (HA) from aqueous solutions. They evaluated five different acids i.e. hydrochloric acid, acetic acid, sulfuric acid, phosphoric acid, and nitric acid. the result of this study, indicated that the modified pumice increased the adsorbent efficiency and the effectiveness of acids on the pumice adsorbent was in the order of $\mathrm{H}_{2} \mathrm{SO}_{4}>$ $\mathrm{HNO}_{3}>\mathrm{H}_{3} \mathrm{PO}_{4}>\mathrm{HCOOH}>\mathrm{HCl}[7]$.
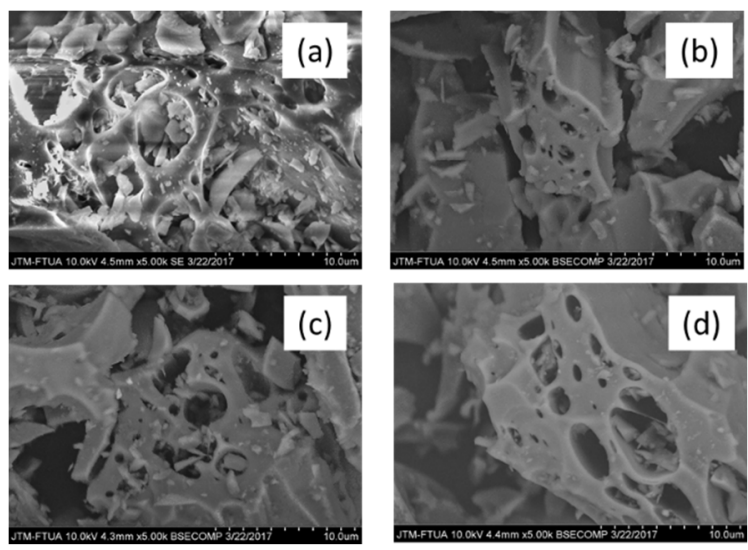

Fig 4. The SEM images (5000x) of natural pumice (a) and chemically modified pumice by acid solution: $\mathrm{HCl}(\mathrm{b}), \mathrm{HNO}_{3}$ (c), and $\mathrm{H}_{2} \mathrm{SO}_{4}$ (d).

The effect of acidic treatment on the surface morphology of pumice is shown in the SEM images of natural and modified pumice, as displayed in Fig 4. Fig 4a shows the pores of natural pumice were largely in number and relatively smooth surface but were covered by other compounds or impurities, as mentioned previously. The uncovered pores and cleaner surfaces were found at the acid-modified pumice, as shown in Fig $4 b-4 d$. The surface of acid-modified pumice also became rugged and more porosity as well as deep cavities, which can be proper sites for adsorption of pollutants. The surface morphology of modified pumice with sulfuric acid has more porosity and heterogeneous than the other samples, as shown in Fig 4d. This condition generated more active adsorption sites and increased removal efficiency as well as the adsorption capacity of pumice. Similar results were also obtained by Soleimani et al. (2019).

The comparison of removal efficiencies and nitrate uptakes obtained by using the natural pumice and modified pumice by heating at $300^{\circ} \mathrm{C}$ and soaking in $\mathrm{H}_{2} \mathrm{SO}_{4} 1 \mathrm{M}$ is summarized in Table 2. These two treatments are the best treatment for physical and chemical modification of pumice which produced the highest removal efficiency and nitrate uptake in the batch adsorption experiment. The physically and chemically modified pumice demonstrated an increase in the removal efficiency and nitrate uptake. The increase was caused by the change in the surface area, pores, and chemical functional groups on the pumice surfaces due to the physical and chemical treatment or modification. Based on the experimental results, it was revealed that various 
treatments of modification could be applied to increase the removal efficiency and nitrate uptake of the pumice. Further investigations should be conducted to find out various treatments for the best technique in the modification of pumice.

Table 2 Comparison of removal efficiencies and nitrate uptakes by using the natural pumice and the physically and chemically modified pumice.

\begin{tabular}{|l|c|c|}
\hline \multicolumn{1}{|c|}{ Kind of adsorbent } & $\begin{array}{c}\text { Removal } \\
\text { Efficiency (\%) }\end{array}$ & $\begin{array}{c}\text { Nitrate } \\
\text { Uptake (mg/g) }\end{array}$ \\
\hline Natural Pumice & 57.02 & 142.55 \\
\hline $\begin{array}{l}\text { Physically modified } \\
\text { pumice } \\
\left.\text { (Heating at } 300^{\circ} \mathrm{C}\right)\end{array}$ & 62.04 & 155.09 \\
\hline $\begin{array}{l}\text { Chemically modified } \\
\text { pumice (Soaking in } \\
\left.\mathrm{H}_{2} \mathrm{SO}_{4} 1 \mathrm{M}\right)\end{array}$ & 83.30 & 208.25 \\
\hline
\end{tabular}

\section{Conclusion}

As one of the efforts for reducing groundwater pollution, the nitrate adsorption onto the physically and chemically modified pumice was studied in the batch system. The physical modification was conducted by heat treatment at $300^{\circ} \mathrm{C}, 450^{\circ} \mathrm{C}$, and $600^{\circ} \mathrm{C}$, while for chemical modification, soaking the pumice in three kinds of acid solution namely $\mathrm{HCl}, \mathrm{H}_{2} \mathrm{SO}_{4}$, and $\mathrm{HNO}_{3}$ with $1 \mathrm{M}$ of concentration were performed. The result shows that the physical and chemical modifications proved to increase the removal efficiency and nitrate uptake. The performance of the heat treatment at $300^{\circ} \mathrm{C}$ was the best temperature for enhancing the removal efficiency and nitrate uptake, compared to natural pumice and heat treatment at $450^{\circ} \mathrm{C}$ and $600^{\circ} \mathrm{C}$. The removal efficiency increases from $57.02 \%$ by the natural pumice to $62.04 \%$, $57.24 \%$, and $29.86 \%$ using modified heating pumice, while nitrate uptake was $142.55 \mathrm{mg} / \mathrm{g}$ by the natural pumice and $155.09 \mathrm{mg} / \mathrm{g}, 143.11 \mathrm{mg} / \mathrm{g}$, and $74.64 \mathrm{mg} / \mathrm{g}$ by modified heating pumice at $300^{\circ} \mathrm{C}, 450^{\circ} \mathrm{C}$, and $600^{\circ} \mathrm{C}$, respectively. For chemical modification, the highest removal efficiency and nitrate uptake $(80.30 \%$ and 208.25 $\mathrm{mg} / \mathrm{g}$ ) were achieved using modified pumice by soaking in $\mathrm{H}_{2} \mathrm{SO}_{4} 1 \mathrm{M}$. The results of SEM analysis demonstrated that physical and chemical treatment modified the pore structure of the natural pumice that could change the surface area and chemical functional group on the surface of the pumice. Overall results were suggested that modification by physical and chemical treatment increased the adsorption capability of pumice in the nitrate removal
The authors are thankful to Universitas Andalas, Indonesia (Grand No. 45/UN.16.17/PP.PGB/LPPM/2018) for supporting this research.

\section{References}

1. A. Bhatnagar and M. Sillanpa, Chem Eng J. 168 493504. (2011)

2. C. H. Liao, S. F. Kang and Y. W. Hsu., Wat Res. 37. 41094118. (2003)

3. D. Helard, S. Indah and M. Oktavia, Wat Sci and Tech: Wat Sup. 20(4). 1484-1492. (2020)

4. M. H. Ward, T. M. deKok, P. Levallois, J. Brender, G. Gulis, B. T. Nolan and J.Van Derslice, Environmental Health Perspective. 113 1607-1614 (2005).

5. M. N. Sepehr, A B. Amrane, K. A. Karimaian, M. Zarrabi, H. R. Ghaffari, J Taiwan Inst Chem Eng. 45 635-647 (2014).

6. S. Indah, D. Helard and A. Binuwara. Wat Sci. Tech. Bonus Issue 2 509-515. (2017).

7. H. Soleimani, A. H. Mahvi, K. Yaghmaeian, A. Abbasnia, K. Sharafi, M. Alimohammadi and M. Zamanzadeh, J Mol Liq. 290111181 (2019).

8. M. Islam, P. C. Mishra and R. Patel, J Enviro Manage. 91 1883-1891 (2010).

9. L. Tribe, R. Hinrichs and J. D. Kubicki, J Phys Chem B. 116 (36) 1266-11273 (2012)

10. J.Y. Kim, M. S. Balathanigaimani and H. Moon, Wat Air Soil Pollut. 226 431. (2015)

11. D.Helard, S. Indah and D. P. Kiflia, IOP Conf Ser: Mat Sci Eng. 846(1) 012059 (2020)

12. A. H. Mahvi and B. Heibati. Res. J. Chem. Enviro. 16 62-68 (2012)

13. S. Indah, D. Helard, T. Edwin and R Pratiwi. AIP Conf Proc. 1823020072 (2017b)

14. S. Indah, D. Helard and F..Hudawaty, Int J Adv Sci Eng Inform Tech. 9 (5) (2019)

15. H. Shayesteh, A. Rahbar-Kelishami and R. Norouzbeigi, J of Mol Liq. 221 1-11 (2016)

16. G M. Walker, L. Hansen, J. A. Hanna and S. Allen, J. Wat Res. 37(9) 2081-9 (2003)

17. W. Shen, Z. Li, and Y. Liu, Rec. Patents Chem. Eng. $127-40$ (2008).

18. M. R. Samarghandi, M. Zarrabi, M. N. Sepehr, A. Amrane, G. H. Safari, and A. Bashiri, Iran Environ Health Sci Eng. 99 (2012)

19. S. D. Gisi, G. Lofrano, M. Grassi and M. Notarnicola, Sustain Mat Tech J. 9 10-40 (2016) 